\title{
The multiple aetiology of viral hepatitis
}

\author{
A. J. ZUCKERMAN \\ Reader in Virology \\ Department of Bacteriology and Immunology, \\ London School of Hygiene and Tropical Medicine, \\ London, WC1E $7 H T$
}

\begin{abstract}
Summary
Infectious hepatitis is epidemiologically and immunologically distinct from serum hepatitis. The Australia antigen is related more specifically to serum hepatitis.

The possible role of coronavirus-and paramyxovirus-like particles in the aetiology of some infections of the liver in man and in marmosets inoculated with human infectious hepatitis material is discussed and the difficulties in the interpretation of the currently available data are emphasized.

The recent studies in Melbourne of a faecal antigen found in some patients with infectious hepatitis and the discovery of an antiserum in Milan which reacted with an antigen associated with epidemic hepatitis are discussed. Mention is made of the recent isolation in Detroit-6 cells of virus-like particles from patients with infectious hepatitis.

It is concluded that viral hepatitis is an infection of multiple aetiology and that the successful cultivation in vitro of the agent or agents of hepatitis remains the outstanding and most urgent problem.
\end{abstract}

\section{Definition}

The usual definition of viral hepatitis is acute inflammation of the liver caused by two infectious agents, presumably viruses, named virus $A$, the aetiological agent of infectious hepatitis or epidemic hepatitis and virus $B$, which is the cause of serum hepatitis or homologous serum jaundice. The definition excludes by common usage acute inflammation of the liver which may be induced by well recognized viruses such as yellow fever, adenoviruses, cytomegalovirus, coxsackie viruses, herpes simplex virus and others (reviewed by Zuckerman, 1970a). It is virtually impossible to distinguish between the two clinically and pathologically similar forms of viral hepatitis. Factors which make such a differentiation even more difficult are that serum hepatitis may be transmitted by the oral route (Krugman, Giles \& Hammond, 1967) and

Correspondence: Dr A. J. Zuckerman, London School of Hygiene and Tropical Medicine, Keppel Street (Gower Street), London, WC1E 7HT. conversely infectious hepatitis may be transmitted parenterally. However, characterization of the infectious type of hepatitis is possible on meticulous epidemiological grounds such as those outlined by Mosley (1970) namely an average incubation period to the onset of symptoms of approximately $\mathbf{3 0}$ days, clear evidence of spread by person-to-person contact or a common source of infection and protection of individuals in the same epidemiological setting by human immunoglobulin in a small dose. Indeed, reference to the nomenclature of infective hepatitis (Table 1), which is bedevilled by a multitude of synonymous terms, reveals a consistent feature throughout: the predominant association of infectious hepatitis with an epidemic setting and the more sporadic nature of serum hepatitis and its association with a parenteral mode of transmission. Furthermore, volunteer experiments have clearly

TABLE 1. The terminology of viral hepatitis

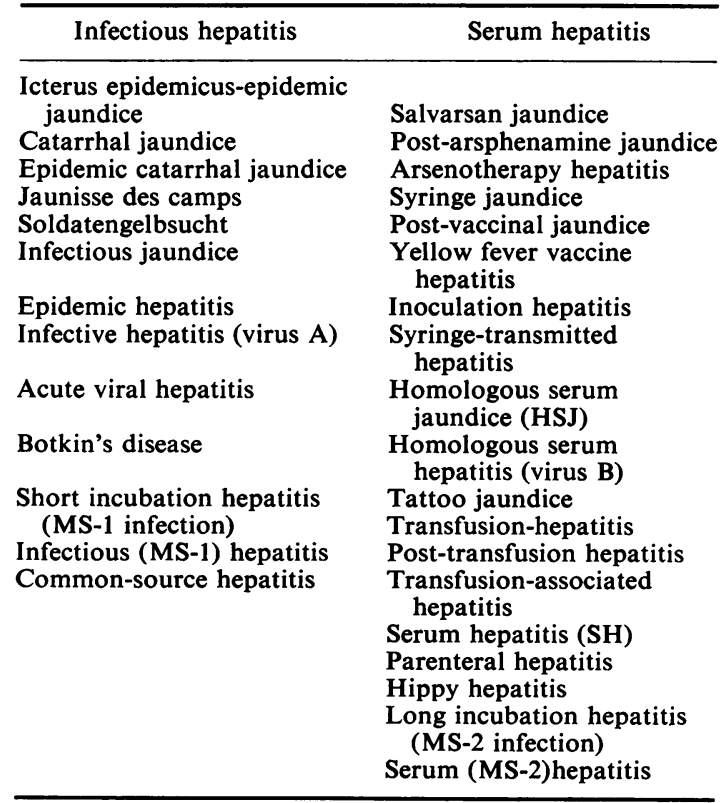


established that these two types of acute hepatitis are caused by aetiologically distinct agents, infectious hepatitis which has a short-incubation period and serum hepatitis with long-incubation.

\section{The Australia antigen}

The discovery of the remarkable association between viral hepatitis and a serum antigen named the Australia antigen (Blumberg et al., 1967) has provided specific serological tests for a proportion of cases of hepatitis. While many conflicting results have been reported on the immunological specificity of the Australia antigen it now appears that this antigen is related more specifically to serum hepatitis or type B viral hepatitis and not epidemic hepatitis (Zuckerman, 1970b, c), although some doubts may be expressed about the viral nature of this antigen (Zuckerman, 1970d; Zuckerman, Taylor \& Bird, 1970).

\section{Coronavirus and paramyxovirus-like particles in hepatitis}

Anticomplementary activity was observed by Patricia E. Taylor \& A. J. Zuckerman in the course of testing sera by complement-fixation for the Australia antigen. Electron microscopic examination of sera from one such patient with chronic active hepatitis revealed the presence of virus particles displaying the typical morphological features of a member of the coronavirus group (Zuckerman, Taylor \& Almeida, 1970). All the virus particles were in association with antibody and the complement-fixing antibody titre to prototype mouse hepatitis virus 3 , a known coronavirus, was $1: 640$. This observation was of interest in view of the analogy with the previous findings of circulating antigenantibody complexes in some patients with serum hepatitis (Taylor, Zuckerman \& Brighton, 1969; Almeida \& Waterson, 1969). The additional finding of high titred antibody crossing serologically with mouse hepatitis virus also raised the possibility that these particles may be a human counterpart to the mouse hepatitis virus.

Deinhardt and his associates (personal communication, 1970) and Holmes et al. (1970) independently observed paramyxovirus-like particles in the acute phase of two patients with infectious hepatitis and in acute phase sera of marmosets with experimentally induced hepatitis. Normal serum specimens and acute phase sera of patients with viral hepatitis and the sera of marmosets were examined in two ways: by caesium chloride density gradient centrifugation and electron microscopy and by testing for infectivity in marmosets. Paramyxovirus-like particles were found in acute phase sera of inoculated marmosets and in acute phase serum specimens of two human patients, one of which also induced hepatitis in marmosets. The fractions with a density of about $1.21 \mathrm{~g} / \mathrm{cm}^{3}$ were infectious for marmosets. Virus-like particles were not found in non-infectious fractions of different densities. An Australia antigen-positive serum and its $1.20 \times 1.25 \mathrm{~g} / \mathrm{cm}^{3}$ and $1.30 \times 1.32 \mathrm{~g} / \mathrm{cm}^{3}$ caesium chloride density gradient fractions were not infectious for marmosets. Further studies are currently in progress to confirm and extend these observations and no firm conclusions should, at this time, be drawn from these findings.

Apodaca et al. (1970) also described coronaparamyxovirus-like particles in marmosets inoculated with human infectious hepatitis material. Five sera were examined under code by Zuckerman, Taylor \& Bird (unpublished observations) and virus-like particles (Fig. 1) were found in the three acute phase sera collected from the inoculated marmosets but not in the serum of the control animals. Hunter et al. (1970) also found paramyxovirus-like particles in a number of patients with chronic liver disease. The significance of coronavirus-like particles together with the structures usually associated with the Australia antigen in a number of serum specimens (Fig. 2) obtained from different patients with hepatitis is impossible to interpret at this stage (Zuckerman, 1970c; Wright, 1970).

More recently Sirtori $(1970 a, b)$ examined by electron microscopy percutaneous liver biopsies obtained from three children with infectious hepatitis who were treated with azathioprine. Many virus-like particles measuring $80-160 \mathrm{~nm}$ in diameter

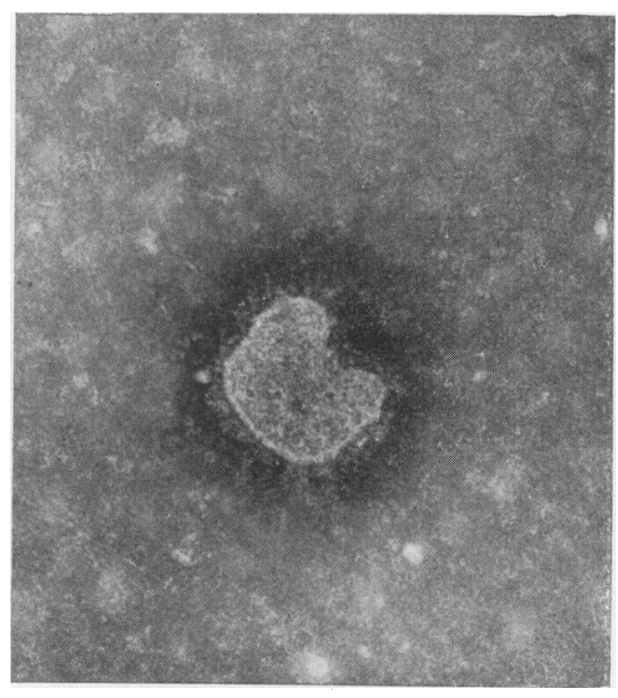

Fig. 1. An example of the particles found in the serum of marmosets inoculated with infectious hepatitis material at the Robert Koch Institute, West Berlin. $\times 88,200$. (Photomicrographs from a series by A. J. Zuckerman, Patricia E. Taylor and R. G. Bird.) 


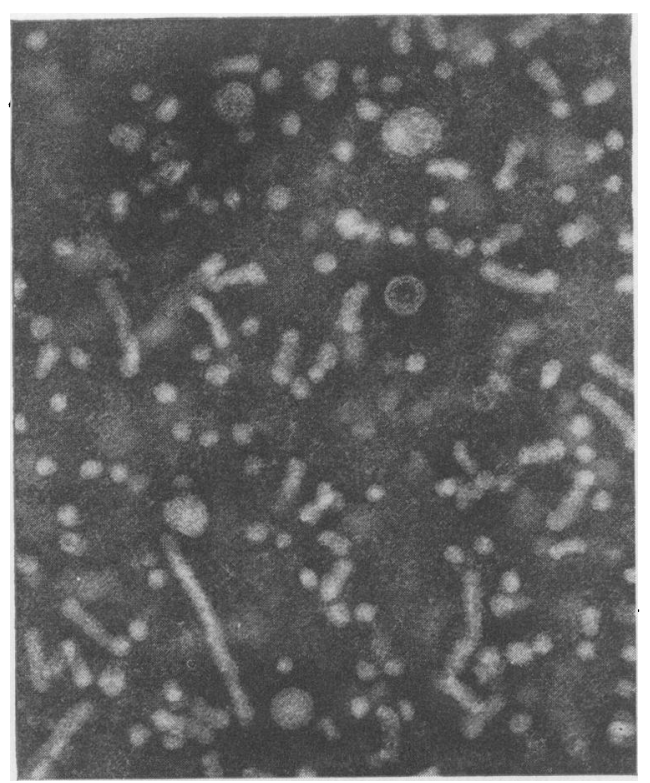

FIG. 2. Serum from a patient with viral hepatitis showing the three typical morphological entities associated with the Australia antigen (small pleomorphic spherical particles measuring $20 \mathrm{~nm}$ in diameter, tubular forms of varying lengths, and large spherical particles measuring $40-45 \mathrm{~nm}$ in diameter) as well as a large particle with radiating clubbed projections. $\times 63,000$.

and displaying the morphology of the coronaparamyxovirus group were found in the cytoplasm of the hepatocytes and Kupffer cells. Some of these particles were shown to be budding from the cell membrane. It is also of interest that serum specimens from these three children reacted in the two dimensional micro-Ouchterlony technique to give precipitin lines with an antiserum possessing specificities for both serum hepatitis (associated with the Australia antigen) and epidemic hepatitis (Del Prete et al., 1970).

However, all these observations are preliminary in nature and they must be interpreted with considerable caution since they do not, of course, prove that these virus-like particles are specifically associated with or are causally related to infectious hepatitis. These virus-like structures may indeed play only a secondary role, if any, in some forms of human liver disease. This view is shared by Zuckerman and his associates and by Deinhardt and his group, and both stress that the data available so far merely indicate possible lines for further investigation.

\section{A faecal antigen in infectious hepatitis}

Ferris et al. (1970) described a faecal antigen in some patients with infectious hepatitis. Bacteriologically sterile supernatants were obtained by high speed centrifugation of a $20 \%$ suspension of faeces collected from six patients with viral hepatitis in whom the Australia antigen was not detected in the serum. The faecal extracts were tested by gel diffusion against sera from thirty-seven multiplytransfused haemophiliacs. Two such sera gave precipitin lines with four of the six faecal extracts, but no reaction was obtained with sera from these patients nor from six patients with other diseases. Two rabbits were immunized with positive faecal extracts which has been purified by fractionation on sucrose gradients. The rabbit antisera were absorbed with normal human serum and twice with faecal extracts from non-hepatitis patients. Single precipitin lines were observed when faecal extracts from ninety out of $220(40.9 \%)$ patients with viral hepatitis and five out of $158(3.1 \%)$ without hepatitis were tested against one of the rabbit antisera. Positively reacting faecal extracts did not react with human or animal anti-Australia antigen sera. Cross and his associates (personal communication, 1970) extended their preliminary observations, and immune electron microscopy indicated the presence of two virus-like particles in the faecal antigen. One particle measures $15-25 \mathrm{~nm}$ in diameter and closely resembles the small particle associated with the Australia antigen (Almeida et al., 1969) and the other is a $40-45 \mathrm{~nm}$ particle also found in many Australia antigen positive sera (Fig. 3) (Dane, Cameron \& Briggs, 1970; Zuckerman, 1970c). Tubular forms were not found in extracts containing the faecal antigen. Cross-serological tests in gel and immune electron microscopy suggest that there are two antigenically distinct types of the small particles, one associated with the Australia antigen and the other associated with the faecal antigen, whereas the larger and somewhat more pleomorphic

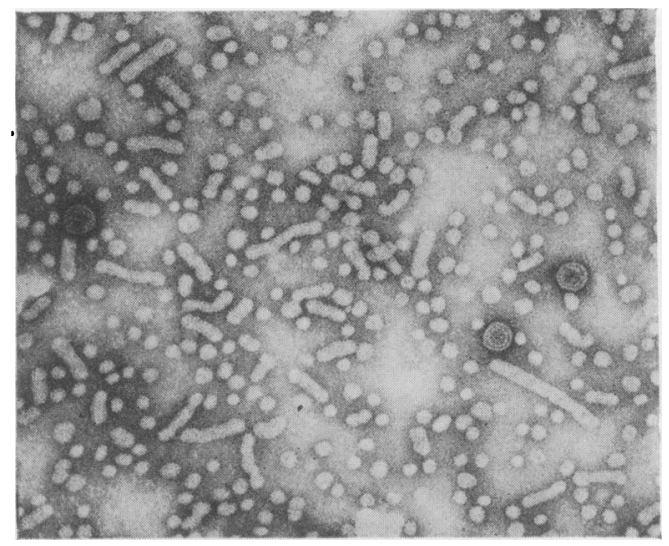

FIG. 3. The typical morphology of the Australia antigen particles found in serum. Note the spherical 'doubleshelled' particles which measure approximately $42 \mathrm{~nm}$ in diameter. $\times 63,000$. 
particles appear to possess a common group component as well as a type-specific component. Further studies of these important observations are in progress.

\section{A serum antigen in epidemic hepatitis}

Recently Del Prete et al. (1970) found a human antiserum in Milan which reacted in the immunodiffusion test with sera from patients with longincubation hepatitis and also with short-incubation hepatitis. This new antiserum detected by gel diffusion a serum antigen associated with classical epidemic hepatitis. A high proportion of sera from three epidemics of short-incubation hepatitis, which were consistently negative with anti-Australia antigen sera tested both by the immunodiffusion technique and by complement-fixation, reacted with the Milan antiserum. Thus a precipitin line was demonstrated in $65 \%$ of 127 patients involved in three separate epidemics of infectious hepatitis and the percentage of positive reactions increased to $90 \%$ in sera obtained during the first week of symptoms. The antigen was cleared from the serum with clinical improvement. This new epidemic hepatitis-associated antigen was found to be remarkably labile, which is a somewhat unexpected finding in view of the known physical stability of the hepatitis agents. It is appreciated, of course, that this antigen might be antigenically distinct from the hepatitis virus in the same way as the $\mathrm{H}$ antigen of poliovirus is antigenically distinct from the antigen on the native virus.

These observations are of great interest since they may ultimately provide specific serological methods for distinguishing between infectious hepatitis and serum hepatitis.

\section{Virus-like particles in infectious hepatitis}

Finally, reference is made to the work of W. A. Rightsel and his associates with the haemoviruses and in particular with the AR-17 agent using the Detroit-6 cell line. This subject was recently reviewed in some detail (Zuckerman, 1970e). Attempts to culture the AR-17 agent in the semi-continuous human embryo liver cell line resulted in a cytopathic effect in these cells which could not be transferred beyond the first passage (Zuckerman et al., 1970). There was no evidence of chromosomal damage in the inoculated cells. Detroit-6 cells inoculated with the AR-17 agent by W. A. Rightsel in Memphis were examined by negative staining and electron microscopy in London in 1969. Pleomorphic particles measuring $18-23 \mathrm{~nm}$ in diameter and arranged in characteristic chainformations and in clumps were found in the inoculated cultures (Fig. 4). It was impossible to interpret the significance of these observations, if any,

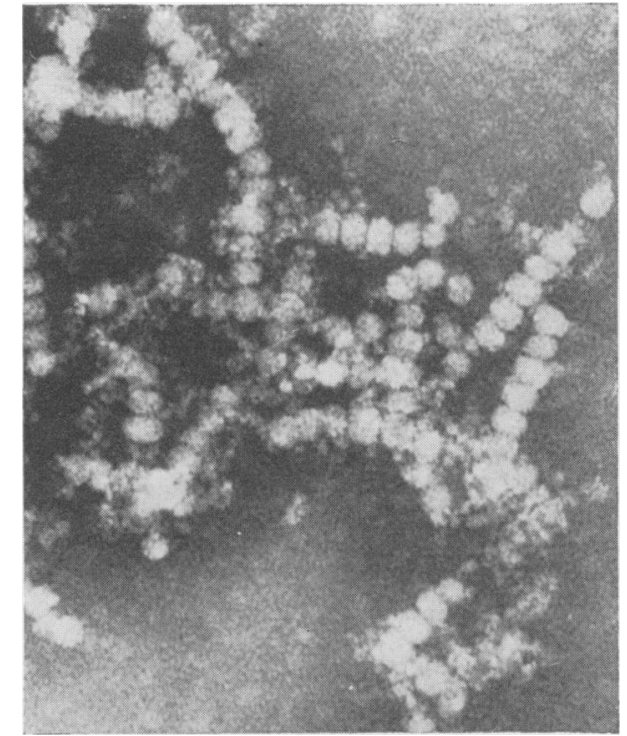

Fig. 4. Pleomorphic particles, measuring approximately $18-23 \mathrm{~nm}$ in diameter, arranged in characteristic chain forms found in the supernatant fluid of Detroit- 6 cells inoculated with the AR-17 agent by W. A. Rightsel. $\times 53,300$.

especially in the absence of other supporting evidence. More recently, Melnick et al. (1970) isolated a virus from the acute phase plasma of a volunteer who developed hepatitis 4 weeks after inoculation with infectious hepatitis serum. This agent produced cytopathic changes in a cloned line of Detroit-6 cells. Particles measuring approximately $18 \mathrm{~nm}$ were found by electron microscopy in material harvested from the infected cells cultures. Similar viruses were also isolated in Detroit- 6 cells from the sera of six other patients with acute infectious hepatitis. Further work is in progress to elucidate the significance of these findings. It is becoming apparent, however, that viral hepatitis should indeed be regarded as an infection of multiple aetiology and the problem could only be resolved by the successful in vitro cultivation of the newly described antigens and agents of hepatitis.

\section{Acknowledgments}

The original work described in this paper was aided by generous grants from the Medical Research Council and in part by laboratory equipment kindly provided by Pfizer Ltd, Sandwich, Kent.

Table 1 is reproduced by kind permission of the Editor of Update.

\section{References}

Almeida, J.D. \& WATERson, A.P. (1969) Immune complexes in hepatitis. Lancet, ii, 983. 
Almeida, J.D., Zuckerman, A.J., TAylor, P.E. \& WaterSON, A.P. (1969) Immune electron microscopy of the Australia-SH (serum hepatitis) antigen. Microbios, 2, 117.

Apodaca, J., TochtermanN, G., Lange, W. \& Köhler, H. (1970) Demonstration of virus-like particles in the serum of monkeys with experimentally induced infectious hepatitis. Zentrablatt für Bakteriologie (1970), 214, 480.

Blumberg, B.S., Gerstey, B.J.S., Hungerford, D.A., LoNDON, W.T. \& SuTNICK, A.I. (1967) A serum antigen (Australia antigen) in Down's syndrome, leukaemia and hepatitis. Annals of internal Medicine, 66, 924.

Dane, D.S., Cameron, C.H. \& BriggS, M. (1970) Virus-like particles in serum of patients with Australia-antigenassociated hepatitis. Lancet, i, 695.

Del Prete, S., Costantino, D., Doglia, M., Graziina, A., AJdukiewicz, A., Dudley, F.J., Fox, R.A. \& SHerlock S. (1970) Detection of a new serum-antigen in three epidemics of short-incubation hepatitis. Lancet, ii, 579.

Ferris, A.A., Kaldor, J., Gust, I.D. \& Cross, G. (1970) Faecal antigen in viral hepatitis. Lancet, ii, 243.

Holmes, A.W., Deinhardt, F., Harris, W., Ball, F. \& Cline, G. (1970) Paramyxoviruses and infectious viral hepatitis. Journal of Clinical Investigation, 49, 45a.

Hunter, J., Carrella, M., Williams, R., Taylor, P.E., ZUCKERMAN, A.J. \& BIRD, R.G. (1970) Hepatitis associated antigen and paramyxovirus-like particles in heroin addicts and patients with chronic liver disease. Proceedings of the Fifth Meeting of the European Association for the Study of the Liver, Berne, p. 21. Hans Huber Publishers, Berne.

Krugman, S., Giles, J.P. \& Hammond, J. (1967) Infectious hepatitis. Evidence for two distinctive clinical, epidemiological and immunological types of infection. Journal of the American Medical Association, 200, 365.

Melnick, J.L., Burkhardt, M., Jordan, L., Jenson, A., Sakurada, N., Hersh, T., Boucher, D.W., Caldwell, E. \& BogGs, J. (1970) Virus from hepatitis patients. Bacteriological Proceedings, Abstract V.153, 177.

MoSLEY, J.W. (1970) Viral hepatitis: recent studies of etiology.
In: Progress in Liver Disease, pp. 252-268. Grune \& Stratton, New York.

SiRTORI, C. (1970a) Virus-like particles in infectious hepatitis. Lancet, ii, 824.

SiRTORI, C. (1970b) Evidenza di virus al microscopio elettronico in biopsie epatiche di bambini con epatiti infettiva trattati con azathioprine. Tentativi di cultura in vitro del virus. Rapporti fra epatite e cancro epatico. Gaslini, $2,5$.

TAYlor, P.E., Zuckerman, A.J. \& Brighton, W.D. (1969) Laboratory tests in viral hepatitis. Journal of Clinical Pathology, 22, 744.

Wright, R. (1970) The Australia antigen in chronic active hepatitis. In: Abstract Volume of the Thirteenth International Congress of Hematology, Munich, p. 216. Lehmanns Vlg., Munich.

ZUCKERMAN, A.J. (1970a) Hepatiticomimetic viruses. In: Virus Diseases of the Liver, pp. 120-127. Butterworth, London.

ZUCKERMAN, A.J. (1970b) Immunological aspects of viral hepatitis. In: Symposium on Advanced Medicine (Ed. by J. D. H. Slater), pp. 133-140. Pitman, London.

Zuckerman, A.J. (1970c) Review of viral hepatitis. Bulletin of the World Health Organization, 42, 957.

ZUCKERMAN, A.J. (1970d) Recent advances in viral hepatitis. Abstracts on Hygiene, 45, 857.

Zuckerman, A.J. (1970e) Attempts to isolate the hepatitis virus by tissue culture methods. In: Virus Diseases of the Liver, pp. 46-53. Butterworth, London.

Zuckerman, A.J., TAYlor, P.E. \& Almeida, J.D. (1970) Presence of particles other than the Australia-SH antigen in a case of chronic active hepatitis with cirrhosis. British Medical Journal, 1, 262.

Zuckerman, A.J., TAYLOR, P.E. \& Bird, R.G. (1970) Antigens and viruses in acute hepatitis. Clinical and Experimental Immunology, 7, 439.

Zuckerman, A.J., TAylor, P.E., Jacobs, J.P. \& Jones, C.A. (1970) Chromosome studies of virus-infected semi-continuous human embryonic liver cells. British Journal of Experimental Pathology, 51, 92. 